\title{
A Rising Challenge in Diagnosis and Prevention: NDM-1 Gene Detection in Acinetobacter Species
}

\author{
P. Lavanya ${ }^{1}$ and A.N. Uma ${ }^{2 *}$ \\ ${ }^{1}$ Department of Microbiology, Faculty of Allied Health Sciences, ${ }^{2}$ Genetic Division, \\ Department of Anatomy, Mahatma Gandhi Medical College and Research Institute, Sri Balaji \\ Vidyapeeth (Deemed to be University), Pondicherry-607 402, India \\ *Corresponding author
}

K e y w or d s
$\begin{aligned} & \text { Metallo- } \beta \text {-lactamase, } \\ & \text { Imipenem, } \\ & \text { Acinetobacter, PCR }\end{aligned}$
Article Info
$\begin{aligned} & \text { Accepted: } \\ & 20 \text { September } 2018 \\ & \text { Available Online: } \\ & 10 \text { October } 2018\end{aligned}$

Acinetobacter, has been identified as an important pathogen in nosocomial outbreaks with high levels of emerging drug resistance. So the present study was conducted in Acinetobacter spp to find out the utility of the multiplex PCR assay, which may be used as a useful technique in the early detection \& prevention of NDM-1 gene harbouring in clinical isolates taken from the patients coming to the tertiary care hospital. Strains of Acinetobacter collected from different clinical samples were subjected to antimicrobial susceptibility testing. Strains which were found showing resistance to imipenem by both disk diffusion and minimum inhibitory concentration (MIC), were analysed for the presence of New Delhi metallo- $\beta$-lactamase genes i.e. NDM-1 (CLASS B) by using multiplex PCR. Among 175 strains of Acinetobacter collected from the clinical samples, 45 strains showed imipenem resistance, both by disk diffusion and MIC out of which 14 (31.1\%) were positive for NDM-1 gene. The present study thus shows that there is dissemination of NDM-1 genes in carbapenem resistant in the Acinetobacter isolates. This scientific evidence can be used to limit the spread of such strains in hospital settings as well as in the community, and also may help in initiating specific hospital infection control measures.

\section{Introduction}

Acinetobacter spp are opportunistic pathogen that can survive for long periods in the hospital environment. Acinetobacter spp are gram negative non-fermentative bacteria (Afzal-shah et al., 2001) Clinical manifestations of Acinetobacter infections includes, hospital acquired pneumonia, blood stream infections, urinary tract infection, meningitis and wound infection (Deniz et al., 2008). Because of frequent resistance to the aminoglycosides and third generation cephalosporin, carbapenem are widely used for managing Acinetobacter infections (Coelho et al., 2004). The emergence of carbapenem resistance in Acinetobacter spp is a significant public health concern because of 
limited option of antibiotic treatment (Fournier and Richet 2006). Carbapenamases found in Acinetobacter may belong to class B (Metallo enzymes) or class D (OXA enzymes) (Weinstein, 1991). The OXA carbapenamases of Acinetobacter is divided into four phylogenetic subgroups namely OXA-23 like, OXA-24 like, OXA-51 and OXA-58. A study done in India has reported the emergence of MBL NDM-1 in different enterobacterial species and also in Acinetobacter (Rolain et al., 2010).

Thus, the present study was carried out to find out if there can be a dissemination of carbapenem resistant NDM-1 genes in Acinetobacter isolates, enabling us to limit the spread of such strains in hospital settings as well as in the community, and also help in initiating specific hospital infection control measures.

\section{Materials and Methods}

The Strains of Acinetobacter were isolated from inpatients of coming to SRM hospital, Chennai, were collected from different samples i.e., sputum, tracheal aspirate, wound swab, blood, urine etc. All isolates were identified to be lactose non fermenting, glucose non-acidifier, Gram negative bacilli, catalase positive, oxidase negative and citrate positive.

\section{Detection of imipenem resistant}

Antimicrobial susceptibility testing was done following Kirby Bauer disk diffusion method using routine drugs including imipenem as per Clinical and Laboratory Standards Institute (CLSI) guidelines. Modified Hodge test and Imipenem EDTA disk synergy test was used to detect carbapenemase production from isolates of Acinetobacter spp and further tested by Minimum inhibitory concentration (MIC) by agar dilution method. The antimicrobial concentration ranges tested were from 0.03 to $128 \mathrm{~g} / \mathrm{ml}$ for imipenem.

\section{Detection of genes by PCR}

DNA extraction was done using multiplex PCR assay on imipenem resistance strains of Acinetobacter, by both disk diffusion and agar dilution method to detect NDM-1 carbapenemases encoding genes as shown below (Pelag et al., 2008).

NDM-1-(100bp)-F-

\section{GCGCAACACAGCCTGACTTT}

\section{R-CACCACCAAAAGCGATGTC}

Amplifications conditions followed in the methodology were, initial denaturation at $94^{\circ}$ $\mathrm{C}$ for 3 mins, 30 cycles of $94^{\circ} \mathrm{C}$ for $1 \mathrm{~min}$, $55^{\circ} \mathrm{C}$ for $1 \mathrm{~min}, 72^{\circ} \mathrm{C}$ for $1 \mathrm{~min}$ and final extension at $72^{0} \mathrm{C}$ for 5 mins.

\section{Results and Discussion}

175 strains of Acinetobacter were isolated from different clinical samples. Among the 175 strains, 61 were found to be resistant to imipenem EDTA disk synergy test (Fig. 1). Of these 61 strains, 45 showed resistance to imipenem by MIC agar dilution method too. Multiplex PCR results showed, that out of total 45 strains of Acinetobacter which were resistant to imipenem by both disk diffusion and MIC agar dilution method,14 (31.1\%) were positive for NDM-1 gene (Fig. 2).

The high antimicrobial resistance of Acinetobacter spp emerged as a nosocomial pathogen worldwide (Pelag et al., 2008). The need for strategic measures to deal with this challenge is to find a solution to minimize antimicrobial misuse within both clinical and non-clinical settings has been stressed by many medical professionals (Richard, 2017). In 1993, acquired OXA carbapenemases was 
reported for the first time and subsequently after that emergence and spread of OXA enzymes have been reported worldwide (Kusradez et al., 2011). Previous reports have indicated that in UK OXA-23 and OXA-51 are most frequently detected in Acinetobacter.

OXA-23 gene is one of the most prevalent carbapenemases encoding genes reported worldwide, which can be located on chromosomes of Acinetobacter plasmids (Mugnier et al., 2010). Similarly in this study all the strains were found to be positive for
OXA-23. OXA-58 may be present along with OXA-23 which is responsible for reduced susceptibility to carbapenem group of drugs. NDM-1 metallo- $\beta$-lactamase was detected among enterobacteriacae and also in Acinetobacter baumannii especially in India and Pakistan. A recent study in India showed the co-existence of OXA-23 and NDM-1 in clinical isolates of Acinetobacter baumannii (Karthikeyan et al., 2010). In our study we used a cost effective multiplex PCR technique and observed only the emergence of NDM-1 in imipenem resistant Acinetobacter isolates.

Fig.1 Double disk synergy test using imipenem EDTA method

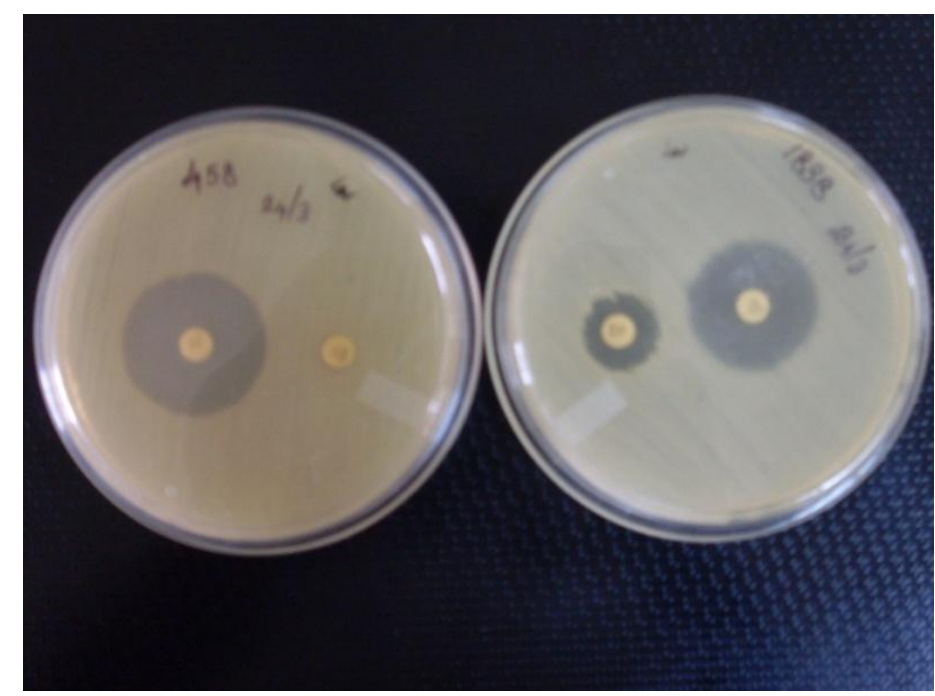

Fig.2 Detection of NDM-1 gene by molecular methods

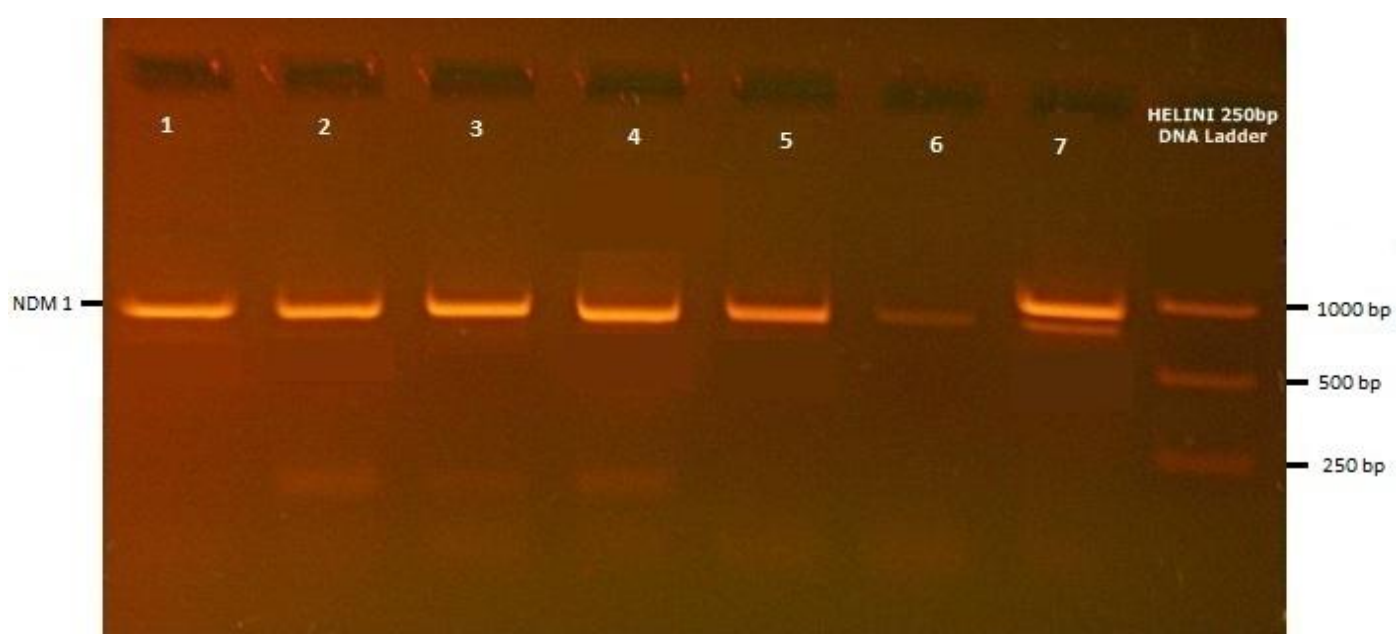


Thus multiplex PCR technique may be very helpful to detect carbapenemase resistant genes at a lower cost and may get the results within a short duration (Nemec, et al., 1999). With increase in drug resistance in Acinetobacter, resistance surveillance has become increasingly important. Hence both the phenotypic and genotypic methods are important to detect the carbapenem resistance in Acinetobacter and technique like Multiplex PCR would help to monitor the emergence and spread of carbapenem resistant Acinetobacter spp (Woodford et al., 2006).

The study successfully demonstrates the utility of the multiplex PCR assay as a useful technique in the detection of NDM-1 harbouring clinical isolates of Acinetobacter. Because of the difficulty in treating patients infected with NDM-1 genes harbouring bacterial pathogens, it is necessary to identify such strains as soon as possible. Moreover, studying the epidemiology of such resistant strains helps us to limit the spread of such strains in hospital settings as well as in the community, and also helps in initiating specific hospital infection control measures.

\section{References}

Afzal-shah, M., Woodford N., Livemore. D.M. Characterization of OXA-25, OXA-26, and OXA-27, molecular class $\mathrm{D}$ beta-lactamases associated with carbapenem resistance in clinical isolates of Acinetobacter baumanni. Antimicrob. Agents Chemother. 2001; 45: 583-588.

Coelho J, Woodford N, Turton J, Livemore DM. Multiresistant Acinetobacter in the UK: how big a threat? J Hosp infect. 2004; 58: 167-169.

Deniz Gur, Volken Korten, Serhat Unal, Lalitagauri M. Deshpande, Mariana Castanheira, Increasing carbapenem resistance due to the clonal dissemination of oxacillinase (OXA-23 and OXA-58) producing Acinetobacter baumannii report from the Turkish SENTRY program sites journal of Medical Microbiology. 2008; 57: 15291532.

Fournier PE, Richet H. The epidemiology and control of Acinetobacter baumannii in health care facilities. Clin infect Dis. 2006; 42: 692-699.

Karthikeyan K, Thirunarayan MA, Krishnan $P$ Coexistence of bla ${ }_{\text {OXA-23 }}$ with bla NDM-1 $_{1}$ and armA in clinical isolates of Acinetobacter baumanni from India $\mathbf{J}$ Antimicrobial Chemotherapy 2010; 65: 2253-2254.

Kusradez la, Diene seydina M, Goderdzishvili Marina, et al., Molecular detection of OXA carbapenemases genes in multidrug resistant Acinetobacter baumannii isolates from Iraq and Georgia.int $\mathbf{J}$ Antimicrob AG. 2011; 38: 164-168.

Mugnier PD, Poirel L, Naas T, et al., Worldwide dissemination of the bla OXA23 carbapenemases gene of Acinetobacter baumannii. Emerg infect Dis. 2010; 16: 35-40.

Nemec, A., L. Janda, O. Melter, and L. Dijkshoorn. Genotypic and phenotypic similarity of multiresistant Acinetobacter baumanni isolates in the Czech Republic. J.Med.Microbiol. 1999; 48.287-296.

Pelag AY, Seifert H, Peterson DL. Acinetobacter baumannii emergence of a successful pathogen. Clin Microbiol Rev. 2008; 21: 538-582.

Richard Ofori-Asenso. "When the Bug Cannot Be Killed"-The Rising Challenge of Antimicrobial Resistance". Medicines. $\quad 2017 ; \quad 4: 40$. doi:10.3390/medicines4020040.

Rolain JM, Parola P, Cornaglia G, et. New Delhi metallo b-lactamase (NDM-1) towards a new pandemia Clin Microbial Infect. 2010; 16: 1699-1701. 
Weinstein A.A. (1991) Epidemiology and control of nosocomial infections in adult intensive care units. Am. J. Med., 91: S179-S184.

Woodford N, Ellington MJ, Coelho JM, Turton IF, Ward ME. Brown S, et al.,
Multiplex PCR for encoding prevalent OXA carbapenemases in Acinetobacter spp. Int J Antimicrob AG. 2006; 27: 351-353.

\section{How to cite this article:}

Lavanya, P. and Uma, A.N. 2018. A Rising Challenge in Diagnosis and Prevention: NDM-1 Gene Detection in Acinetobacter Species. Int.J.Curr.Microbiol.App.Sci. 7(10): 2846-2850.

doi: https://doi.org/10.20546/ijcmas.2018.710.331 